\title{
Benefits from the U.S. Photovoltaic Manufacturing Technology Project
}

R.L. Mitchell, C.E. Witt, H.P. Thomas, L.O. Herwig, D.S. Ruby, and C.C. Aldrich Presented at the 25th IEEE Photovoltaic Specialists Conference, May 13-17, 1996, Washington, D.C.

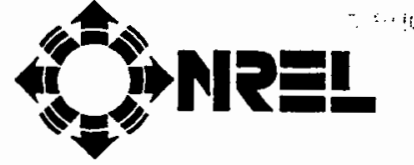

National Renewable Energy Laboratory 1617 Cole Boulevard Golden, Colorado 80401-3393

A national laboratory of the U.S. Department of Energy Managed by Midwest Research Institute for the U.S. Department of Energy under contract No. DE-AC36-83CH10093

Prepared under Task No. PV650101

May 1996 


\section{NOTICE}

This report was prepared as an account of work sponsored by an agency of the United States government. Neither the United States government nor any agency thereof, nor any of their employees, makes any warranty, express or implied, or assumes any legal liability or responsibility for the accuracy, completeness, or usefulness of any information, apparatus, product, or process disclosed, or represents that its use would not infringe privately owned rights. Reference herein to any specific commercial product, process, or service by trade name, trademark, manufacturer, or otherwise does not necessarily constitute or imply its endorsement, recommendation, or favoring by the United States govemment or any agency thereof. The views and opinions of authors expressed herein do not necessarily state or reflect those of the United States government or any agency thereof.

Available to DOE and DOE contractors from:

Office of Scientific and Technical Information (OSTI)

P.O. Box 62

Oak Ridge, TN 37831

Prices available by calling (423) 576-8401

Available to the public from:

National Technical Information Service (NTIS)

U.S. Department of Commerce

5285 Port Royal Road

Springfield, VA 22161

(703) $487-4650$ 


\title{
BENEFITS FROM THE U.S. PHOTOVOLTAIC MANUFACTURING TECHNOLOGY PROJECT
}

\author{
Richard L. Mitchell, ${ }^{1}$ C. Edwin Witt,, ${ }^{1}$ Holly P. Thomas, ${ }^{1}$ Lloyd O. Herwig, ${ }^{2}$ Douglas S. Ruby, ${ }^{3}$ Clay C. Aldrich ${ }^{4}$ \\ 1 National Renewable Energy Laboratory, Golden, CO; 2 U.S. Department of Energy, Washington, D.C.; \\ 3 Sandia National Laboratories, Albuquerque, NM; and 4 Solar Energy Industries Association, Washington, D.C.
}

\begin{abstract}
This paper examines the goals of the Photovoltaic Manufacturing Technology (PVMaT) project and its achievements in recapturing the investment by the photovoltaic (PV) industry and the public in this research. The PVMaT project was initiated in 1990 with the goal of enhancing the world-wide competitiveness of the U.S. PV industry. Based on our analysis, PVMaT has contributed to PV module manufacturing process improvements, increased product value, and reductions in the price of today's PV products. An evaluation of success in this project was conducted using data collected from 10 of the PVMaT industrial participants in late fiscal year (FY) 1995. These data indicate a reduction of $56 \%$ in the weighted average module manufacturing costs from 1992 to 1996 . During this same period, $U$. module manufacturing capacity has increased by more than a factor of 6 . Finally, the analysis indicates that both the public and the manufacturers will recapture the funds expended in R\&D manufacturing improvements well before the year 2000 .
\end{abstract}

\section{BACKGROUND}

The Photovoltaic Manufacturing (PVMaT) project was started in 1990 to help U.S. industry extend its world leadership role in manufacturing and commercially developing PV modules and systems. It is a U. Department of Energy/U. industry cost-shared program that focuses on identifying and improving manufacturing processes that affect the cost and production of PV modules and systems. Each candidate project is evaluated on its own technical merit and its promise for contributing to the PVMaT goals, independent of the technology being proposed or of other projects that might be selected for funding. Furthermore, organizations interested in the various photovoltaic technologies have been equally eligible to respond to the procurements and to make their case for participation in this manufacturing technology project.

PVMaT was designed to help the U. PV industry improve manufacturing processes, accelerate manufacturing cost reductions for PV modules, improve commercial product performance, and lay the groundwork for a substantial scale-up of U.S. PV manufacturing plant capacities. Four separate phases comprise the PVMaT project to date. Each phase was designed to address selected R\&D activities required to achieve PVMaT goals and support the specific needs of the PV industry.

Phase 1 was a problem-identification phase of about 3 months duration. It consisted of 22 small (less than $\$ 50,000$ of DOE funding each) subcontracts resulting from 38 offers. During Phase 1, the status and needs of the U.S. PV manufacturing industry were identified, and a Phase 2 procurement responsive to industry's needs was developed. The Phase 1 subcontracts were completed in 1991.

Phase 2 addressed process-specific module manufacturing problems of individual manufacturers. The first solicitation under this-phase (Phase 2A) was open only to organizations that received awards under the Phase 1 solicitation. Seven 3-year subcontracts were initiated in early 1992 and have been completed. The next PVMaT Phase 2 effort (Phase 2B) was a solicitation open to all U.S. $P V$ industrial firms This allowed organizations not ready for the earlier Phase 2A procurement cycle, or which were not participants in Phase 1, to have a chance to "ramp on" and participate in this process-specific solution phase of the PVMaT project. Four 3-year subcontracts, selected from 13 proposers, were awarded under this solicitation in late 1993.

Phase $3 \mathrm{~A}$ addressed generic module manufacturing needs using a team approach. Seven proposals were submitted in response to the solicitation. Two subcontracts were awarded in January of 1993.

Phase 4A, Product-Driven Manufacturing, is the next step in the phased PVMaT project. It is a broader approach to addressing the overall goal of improved U.S. market share by meeting the market challenges. The solicitation requested proposals from individual or teamed U.S. PV and related industries to address the manufacturing of PV endproducts, as well as the sub-elements of these products. Proposers could be firms or teams that may not be typically associated with PV systems, components, or products, but may have applicable expertise. The objectives of this phase were to stimulate broader interest in the production of PV products. They were also to encourage and support risktaking by industry to explore new manufacturing options and ideas for improved PV products or components, influence system and product integration, and stimulate advances in balance-of-systems or developments in design that will lead to the overall reduced system life-cycle costs of the PV endproduct. The thrust is to emphasize the importance of cost reduction, improved efficiency, and manufacturing flexibility and broader market applications for PV systems as a whole. 
To accomplish the Phase 4A goals, the solicitation was divided into two parts: (1) Product-Driven System and Component Technology-4A1, with goals of improving integration efficiency, advancing design elegance, and improving component integration and manufacturing, and (2) Product-Driven PV Module Manufacturing Technology-4A2, addressing manufacturing flexibility and module manufacturing cost reduction for a wider range of PV products. Thirteen awards, selected from 31 proposals, have been made in Phase 4A: eight in Phase 4A1 and five in $4 \mathrm{A2}$.

Total funding for PVMaT, including both federal and industry cost-share, and including projected funding to the end of PVMaT 4A, is $\$ 118$ million. Cost-sharing by industry will total about $43 \%$. Figure 1 shows a breakdown of the anticipated total funding by technology for both the DOE contribution and the subcontractor cost-shares. The technology areas are crystalline silicon (c-Si), concentrators (Conc), amorphous silicon (a-Si), cadmium-telluride-based systems (CdTe), copper-indium-diselenide-based systems (CIS), and general (Gen). The general area includes generic efforts in areas such as encapsulation, system integration, and balance-of-systems.

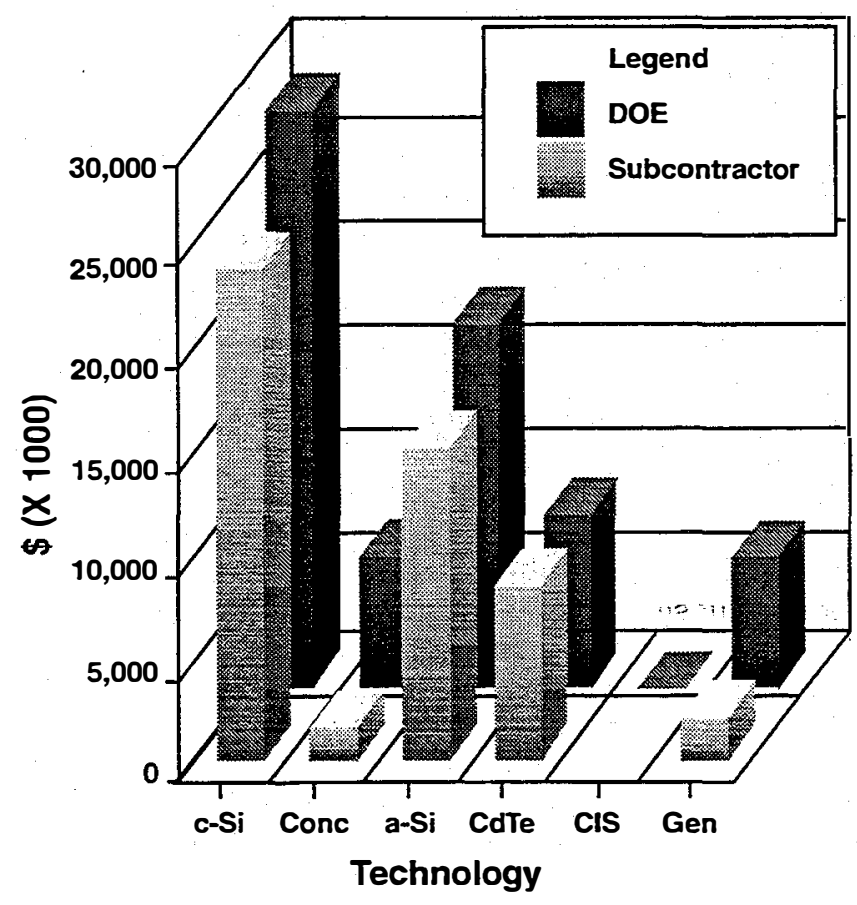

Figure 1. Cost-sharing by technology.

\section{GOALS}

The goals of PVMaT are to work jointly with the U.S. PV industry to improve manufacturing processes, accelerate manufacturing cost reductions for PV modules, improve commercial product performance, and lay the groundwork for a substantial scale-up of U.S.-based PV manufacturing plant capacities. Obvious elements for measurement are the cost reductions and the manufacturing capacities and volumes. But to actually evaluate the benefits to manufacturers and users, one must look at how these advances can be translated into savings. The following sections in this paper present the expected recapture of funds spent on the manufacturing R\&D performed under PVMaT Phases $2 \mathrm{~A}$ and 2B. Other participants (e.g., 4A2 participants) were not included because we felt they had not been involved long enough to have made cost impacts under PVMaT. The baseline from which these benefits are measured is based on 1992 data, which corresponds roughly to the initiation of Phase 2 efforts.

\section{DISCUSSION}

Progress of the individual industrial PVMaT participants has been described in published subcontractor reports and conference papers. Although this information on improvements in manufacturing processes was very encouraging, it was difficult to relate this progress to the progress of the PVMaT project as a whole. To get a better idea of progress toward accomplishing its goals of accelerating manufacturing cost reductions and stimulating a scale-up in capacity, the PVMaT manufacturing participants involved in Phases $2 \mathrm{~A}$ and $2 \mathrm{~B}$ were asked to provide specific data regarding their module manufacturing costs and capacity. For each year from 1992-2000, the industrial participants were asked to include costs directly associated with their module production, including manufacturing overhead costs. They were asked to exclude categories such as marketing, sales, administration, or the overhead associated with these areas. Capacity data were to represent the levels at which a manufacturer was capable of producing, based on equipment in place at the time, required maintenance, individual company policies, and unlimited product orders. These data, representing plant capabilities and company business plans, are considered highly sensitive by the individual companies. Therefore, Fig. 2 presents aggregate data in the form of a weighted average of module manufacturing costs and a summation of the manufacturing capacity (in place in each year through 1995 and projected for later years) for the 10 industrial participants that currently have active production lines. The weighted average represents the average cost per watt of modules (weighted by each participant's capacity) produced by these 10 PVMaT industrial participants. Figure 2 indicates that PV manufacturing capacity has increased by more than a factor of 6 in the last 4 years, from 11.6 MW to 88.7 MW. Additionally, the weighted-average cost for manufacturing PV modules has been reduced by about $56 \%$. Although we saw these as important results regarding the progress the U.S. PV industry was making toward regaining its international competitiveness, it was still not clear how much of this progress should be attributed to the PVMaT project. 


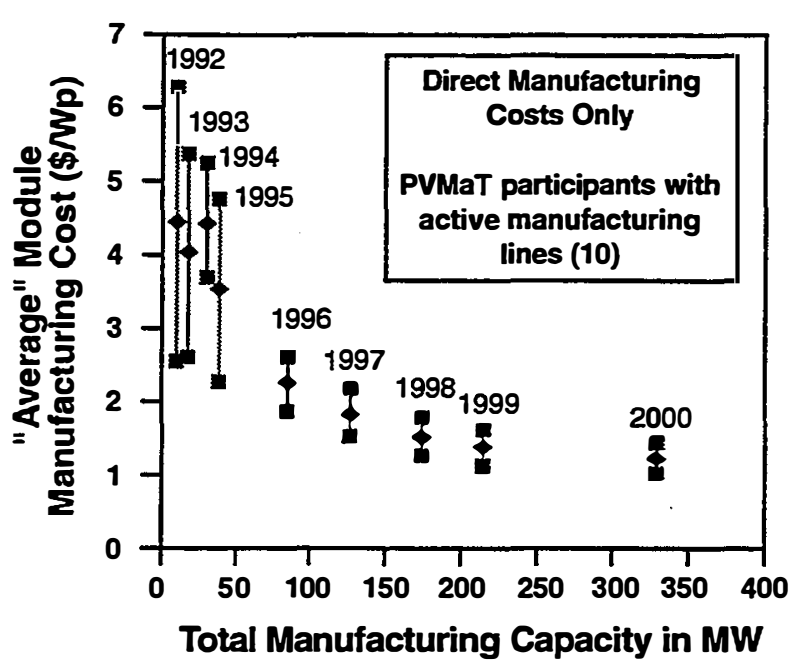

Figure 2. PVMaT Manufacturing cost/capacity.

To further address the impact of the PVMaT project, information was requested from the PVMaT participants on the payback from their R\&D progress. Each of the 10 PVMaT manufacturers was asked to identify, by year, the specific technical improvements that have resulted in cost reductions for their product. They also established the value in \$/watt for each of their improvements. Finally, manufacturers were asked to identify what portion of each improvement cost reduction they would pass on to the public as price reductions and how much would be used by the companies as internal reductions in their manufacturing costs. The data provided by the PVMaT manufacturers represented improvements in module fabrication such as improved junction:boxes and improvements in module performance. The module performance improvements were, however, only taken as a cost reduction when the power output increase and the concomitant module cost reflected an actual reduction in $\$ /$ watt.

The annual and cumulative data on the recapturing of funds spent on this research by the individual companies and the public were analyzed from the initiation of each subcontract to identify the magnitude of the benefit to each participant. Because benefit to either the public or the manufacturer would not be realized if the products were not actually manufactured, actual and projected production levels (as opposed to manufacturing capacities) provided by the individual manufacturers were used in calculating the annual dollars saved. Additionally, the value of these benefits would not be realized unless they represented competitive products; therefore, the analysis used only the cost reductions that reduced the cost of manufacturing below the $\$ 4.50 /$ watt weighted average that the PVMaT participants reported for 1992 . No benefit was accrued to either the individual companies or to the public until this level of cost had been achieved, and only the portion that represented a value below this level was used in subsequent years. Improvements that are to be used in all future product manufacturing, such as improved encapsulation configurations, will be of benefit in all subsequent-year products and were included in those years. Finally, the public benefit results of this analysis were normalized to the funding provided by the DOE. Data for the industrial participants were normalized to their costshared portion of the PVMaT subcontract.

As can be seen in Fig. 3, both the public and industry have benefited in this research. The public will recapture its portion of the funds spent on this research in 4.1 years through a direct reduction in the price of PV products. If only the U.S. sale of these PV products is used, at approximately $30 \%$ [1] of the production volume, the public savings due to price reductions will result in the U.S. public recapturing its portion of the funds spent in about $\mathbf{5 . 2}$ years. However, this approach does not take into account the value recaptured by the U.S. public through an increase in world market share and jobs, and an improved trade deficit.

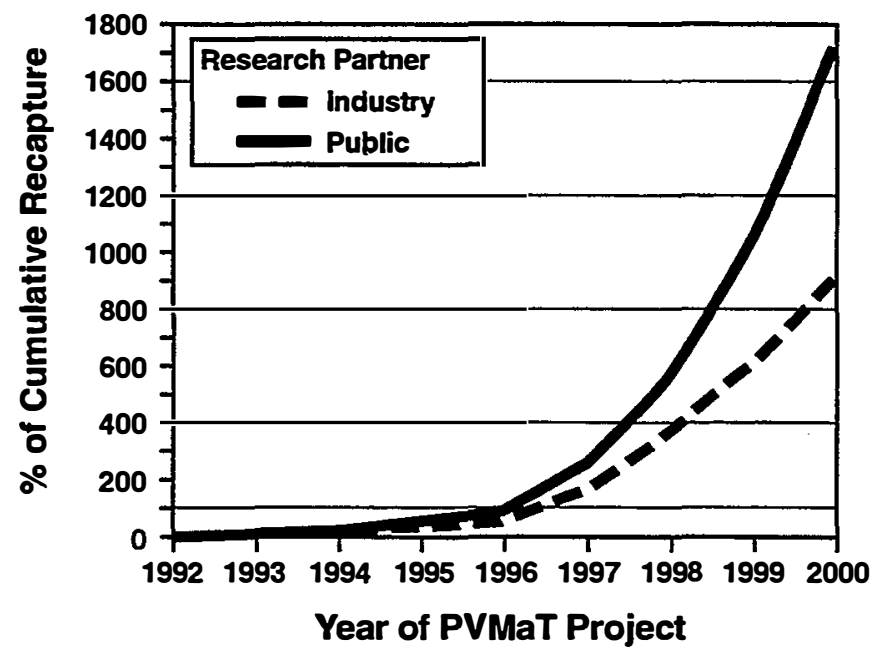

Figure 3. Recapture of PVMaT Research Funding. (U.S. and international sales)

The 10 PVMaT manufacturers with active production lines will recapture the funds they have individually costshared in an average of 2.8 years from the start of their subcontracts. The aggregate funds cost-shared by PVMaT industrial partners will have been recaptured in 4.4 years. This benefit may take any of several forms, such as decreased losses, increased profits, investment in increased production capacity, or performance of additional R\&D.

The results shown in Fig. 3 represent the benefits achieved by the 10 industrial participants that currently have active production lines. The industry benefits are only for these 10. However, the public investment in other PVMaT industrial partners (those who are not currently active in the manufacturing of PV products) was included in the public costs requiring recapture. If current production projections by the 10 PVMaT participants are accurate, the public will have recouped over 17 times its original investment in the 
PVMaT Phase $2 \mathrm{~A}$ and Phase $2 \mathrm{~B}$ research efforts by the year 2000. If, as above, only the U.S. sale of these PV products at the $30 \%$ level is used, the recoupment is still 5 times the original investment. The industrial participants will have also shared in benefits from their cost-shared participation in this research, with recovery of almost 9 times their investment by the year 2000. Even if these are optimistic predictions (and predictions often are), it seems very likely that the investment in PVMaT through Phase 2B will more than have been recovered before the end of the decade.

Finally, what has happened to the U.S. PV market share? Figure 4 shows the U.S. market share fell to about $31 \%$ in 1992 , the first vear of the PVMaT 2B efforts. Since

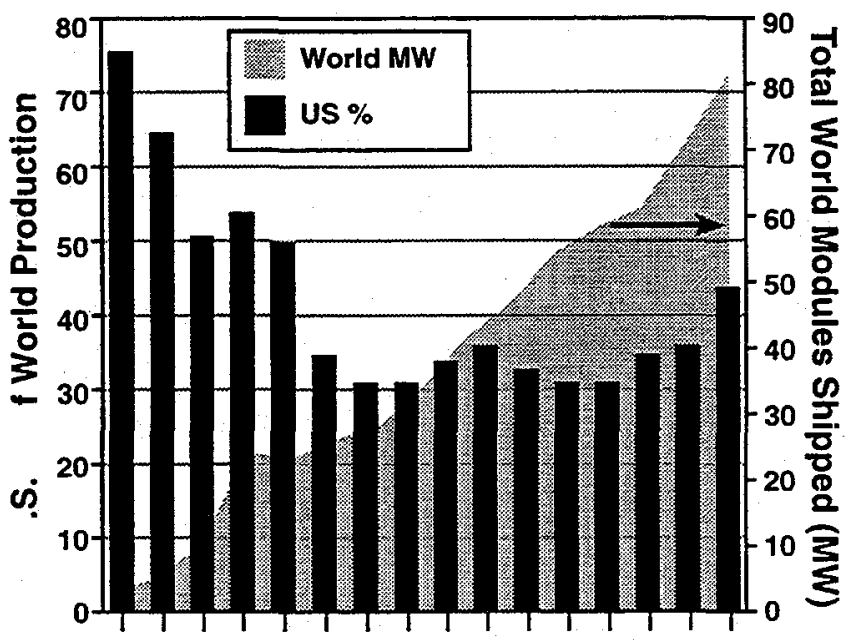

Year

Figure 4. U.S. market share of world production.

We believe elements of this strengthening position include a new generation of PV modules with improved performance and durability, as well as advanced and refined module manufacturing processes. These modules have been developed with the help of government/industry partnerships that are the cornerstone of the PVMaT project. The efforts of industry and the government/industry partnerships have all contributed to PV technology and market status improvements, and PVMaT has been a significant contributor to those benefits.

We intend to continue to update both cost and capacity data for the manufacturers in real time. Additional improvements to be gained as Phase $2 \mathrm{~B}$ subcontracts reach their end and new research results from the current Phase $4 \mathrm{~A} 2$ subcontracts are obtained will also be included in future evaluations on the PVMaT benefits to industry and the U.S. public.

\section{CONCLUSIONS}

PVMaT Phases 2A, 2B, and 3A are near completion. An evaluation of the information now available indicates PVMaT is a success in achieving increased production and lower cost. Data collected in late FY 1995 from 10 PV manufacturing lines participating in the PVMaT project have allowed an evaluation of the success of this project. Increased production capacity, reduced modulemanufacturing direct costs, and the recapturing of funds spent in PV manufacturing R\&D have been reported by the PVMaT Phase 2 participants. The weighted average module manufacturing cost has declined an estimated $56 \%$ and production capacity has increased by more than a factor of 6 in the last 4 years. Recapture of the funds spent for manufacturing improvements is achieved in about 5 years, and by the year 2000, it will significantly exceed the investment by the U.S. public and the U.S. manufacturers. Finally, the late-1980s/ early-1990s decline in U.S. PV manufacturing market share of world production has reversed. U.S. market share has risen to $43 \%$ in 1995 , after falling to a low of about $30 \%$ in 1992 . The U.S. PV industry is getting stronger, and the PVMaT government/industry collaboration is contributing to a growing U.S. PV technology with a positive recapture of investments in manufacturing R\&D.

\section{ACKNOWLEDGEMENTS}

This work is supported under DOE contract No. DEAC36-83CH10093 with NREL. Many people have contributed to the development and implementation of the Photovoltaic Manufacturing Technology project and to the R\&D efforts carried out in this program. The authors recognize this paper represents their work, and it is those people who are the real authors of the accomplishments presented. We thank them, each and every one.

\section{REFERENCES}

[1] Data for figure developed from the following sources: PV Insiders Report, Vol. XIfli, No. 2, 1994, p. 1.

PV News, Vol. 3, No. 2, 1984, p. 2.

PV News, Vol. 15, No. 2, 1996, p. 3.

Solar Energy Intelligence Report, Set. 9, 1986, p. 81.

The World PV Market, July 1985, p. 50.

Solar Collector Manufacturing Activity, 1993, DOE/E1AV174 (93), Aug 1993, p. 19. 